\title{
Ultrasound assessment of gastric content in fasted patients before elective laparoscopic cholecystectomy: a prospective observational single-cohort study
}

\section{Évaluation échographique du contenu gastrique chez des patients à jeun avant une cholécystectomie non urgente par laparoscopie : une étude prospective observationnelle sur cohorte unique}

\author{
Jee-Eun Chang, MD $\cdot$ Hyerim Kim, MD $\cdot$ Dongwook Won, MD $\cdot$ Jung-Man Lee, MD, \\ PhD $\cdot$ Ji-Yoon Jung, MD $\cdot$ Seong-Won Min, MD, PhD $\cdot$ Jin-Young Hwang, MD, PhD
}

Received: 3 August 2019/Revised: 12 November 2019/Accepted: 21 November 2019/Published online: 20 April 2020

(C) Canadian Anesthesiologists' Society 2020

\begin{abstract}
Background Patients with symptomatic gallbladder diseases exhibit delayed gastric emptying. We evaluated the residual gastric content in fasted patients scheduled for elective laparoscopic cholecystectomy because of symptomatic gallbladder disease using ultrasonography.

Methods This prospective observational single-cohort study was approved by the Institutional Review Board, and written informed consent was obtained from all included patients. Before anesthesia induction, the gastric antrum was examined by ultrasound. Once the presence of solid content was excluded, the patients were classified using a three-point grading system (grade 0: no fluid;
\end{abstract}

This article is accompanied by an editorial. Please see Can J Anesth 2020; 67: this issue.

J.-E. Chang, MD · H. Kim, MD · D. Won, MD · J.-M. Lee, MD, $\mathrm{PhD}$

Department of Anesthesiology and Pain Medicine, SMG-SNU Boramae Medical Center, Boramae-ro 5, Dongjak-gu, Seoul 07061, Republic of Korea

J.-Y. Jung, MD

Department of Anesthesiology \& Pain Medicine, Seoul National University Hospital, Seoul, Republic of Korea

S.-W. Min, MD, PhD · J.-Y. Hwang, MD, PhD ( $\square)$

Department of Anesthesiology and Pain Medicine, SMG-SNU Boramae Medical Center, Boramae-ro 5, Dongjak-gu, Seoul 07061, Republic of Korea

e-mail: mistyblue15@naver.com

College of Medicine, Seoul National University, Seoul, Republic of Korea grade 1: fluid in the right lateral decubitus position; grade 2: fluid in both the supine and right lateral decubitus positions), and the fluid volume was measured. A stomach was considered empty if it had no contents or $\leq 1.5$ $m L \cdot \mathrm{kg}^{-1}$ of fluid, and was considered full if solid content or $>1.5 \mathrm{~mL} \cdot \mathrm{kg}^{-1}$ of fluid was detected.

Results Among 138 patients, 18 patients (13\%) presented with a full stomach, 12 (9\%) of whom had solid content, and six (4\%) of whom had $>1.5 \mathrm{~mL} \cdot \mathrm{kg}^{-1}$ of fluid in their stomach. Among the remaining 120 patients with an empty stomach, 65 patients presented with a grade 0 antrum, and 55 patients with a grade 1 or 2 antrum with $\leq 1.5 \mathrm{~mL} \cdot \mathrm{kg}^{-1}$ of fluid.

Conclusion The gastric ultrasound assessment revealed that $13 \%$ of patients scheduled for elective cholecystectomy because of symptomatic gallbladder disease had a full stomach despite following the fasting guidelines. This was higher than the reported incidence of a full stomach among the general surgical population. Further studies are required to delineate the clinical implications of our findings.

Trial registration $w w w$.ClinicalTrials.gov (NCT03259841); registered 4 August, 2017.

\section{Résumé}

Contexte Les patients atteints de maladies vésiculaires symptomatiques souffrent de retard de la vidange gastrique. Nous avons évalué par échographie le contenu gastrique résiduel chez des patients à jeun devant subir une cholécystectomie non urgente par laparoscopie en raison de maladie vésiculaire symptomatique. 
Méthode Cette étude prospective observationnelle sur une cohorte unique a été approuvée par le Comité d'éthique indépendant et le consentement éclairé écrit a été obtenu de tous les patients inclus. Avant l'induction de l'anesthésie, l'antre gastrique a été examiné par échographie. Une fois la présence de solides exclue, les patients ont été catégorisés selon un système de notation de 3 grades $(0$ : aucun liquide; 1 : liquides détectés en position de décubitus latéral droit; 2 : liquides détectés en décubitus dorsal et en décubitus latéral droit), et le volume liquidien a été mesuré. Un estomac était considéré comme vide s'il n'avait aucun contenu solide et $\leq 1,5 \mathrm{~mL} \cdot \mathrm{kg}^{-1}$ de liquides, et considéré comme plein si du contenu solide ou $>1,5 \mathrm{~mL} \cdot \mathrm{kg}^{-1}$ de liquides était détecté.

Résultats Parmi 138 patients, $18(13 \%)$ se sont présentés avec un estomac plein, parmi lesquels 12 (9\%) avaient du contenu solide, et six (4\%) avaient $>1,5 \mathrm{~mL} \cdot \mathrm{kg}^{-1}$ de liquides dans l'estomac. Parmi les 120 patients restants avec un estomac vide, 65 présentaient un antre gastrique de grade 0 et 55 présentaient un antre de grade 1 ou 2 avec $\leq 1,5 \mathrm{~mL} \cdot \mathrm{kg}^{-1}$ de liquides.

Conclusion L'évaluation gastrique par échographie a révélé que $13 \%$ des patients devant subir une cholécystectomie non urgente en raison de maladie vésiculaire symptomatique avaient un estomac plein tout en ayant respecté les directives de jeûne. Ce chiffre était plus élevé que l'incidence rapportée d'estomac plein parmi la population chirurgicale générale. Des études supplémentaires sont nécessaires pour déterminer les implications cliniques de nos résultats.

Enregistrement de l'étude $w w w$.ClinicalTrials.gov (NCT03259841); enregistrée le 4 août 2017.

General anesthesia depresses lower esophageal sphincter tone and upper airway protective reflexes, thereby increasing the risk of aspiration. ${ }^{1,2}$ Perioperative aspiration can lead to serious complications such as aspiration pneumonia, and the mortality rate for aspiration pneumonia has been reported to be $5 \%{ }^{3}$ Residual gastric content is one of the most important risk factors for aspiration pneumonia. ${ }^{4}$ Thus, patients scheduled to undergo elective surgery are asked to undergo preoperative fasting to prevent pulmonary aspiration during the perioperative period. Nevertheless, the conventionally recommended fasting times (a minimum of two hours after consumption of clear fluid, six hours after consumption of a light meal, and eight hours after consumption of fried or fatty food) ${ }^{5}$ may not guarantee an empty stomach in patients at risk factors of aspiration ${ }^{6-8}$ and even in some healthy patients. ${ }^{9,10}$ Indeed, according to some studies that used gastric ultrasonography, 2.7-6.2\% of fasted patients had a full stomach before elective surgery. ${ }^{9,10}$

Cholecystectomy is one of the most common elective abdominal surgeries. ${ }^{11}$ Patients undergo cholecystectomy mainly because of symptomatic gallbladder diseases such as cholecystitis; further, compared with normal control subjects, patients with symptomatic gallbladder diseases have been reported to exhibit delayed gastric emptying. ${ }^{12}$ Although rare, gallstone ileus can occur as a complication of acute cholecystitis. ${ }^{13}$

Bedside ultrasonography is an emerging diagnostic tool for evaluating the type and volume of gastric content. ${ }^{14,15}$ Several studies have reported the gastric status of preoperative fasted patients with risk factors for aspiration using ultrasonography. ${ }^{6-8}$ Nevertheless, the preoperative gastric status of patients before cholecystectomy has not been evaluated yet. Therefore, this study was designed to assess the type and amount of residual gastric content using ultrasonography in fasted patients scheduled for elective laparoscopic cholecystectomy because of symptomatic gallbladder disease.

\section{Methods}

This study was approved by the Institutional Review Board of our hospital (20170822/30-2017-31/093), and registered prior to patient enrolment at ClinicalTrials.gov (NCT03259841). After obtaining written informed consent, adult patients who were scheduled to undergo elective laparoscopic cholecystectomy because of symptomatic gallbladder disease were recruited for this study. Patients who had gastric anatomic abnormalities or pathologies, a previous history of surgeries on the esophagus or stomach, were pregnant, or could not lie down in the right lateral decubitus (RLD) position were excluded. The included patients followed institutional fasting guidelines (a minimum of two hours for clear fluid and eight hours for solid intake).

Before anesthesia was induced on the day of surgery, a gastric ultrasound examination was performed using an ultrasound system with a $2-5 \mathrm{MHz}$ curved array transducer (CX 50; Philips Healthcare, Andover, MA, USA) and with the patients first in the supine position followed by the RLD position as previously described. ${ }^{16}$ This examination was performed by two staff anesthesiologists with ten years of experience using ultrasonography for other clinical applications and two years of experience performing ultrasonographic gastric assessment. The transducer was placed along the sagittal plane of the epigastric area, and the gastric antrum was visualized in the parasagittal plane, 

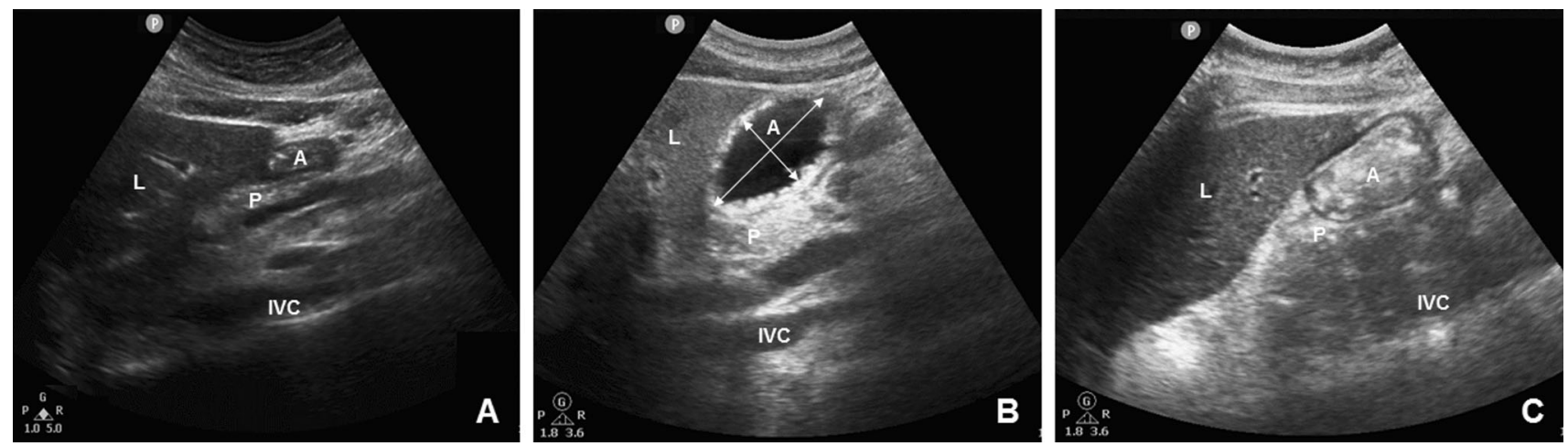

Figure Ultrasonographic images of the gastric antrum in the right lateral decubitus position. The gastric antrum appears collapsed and flat in an empty stomach (A). The gastric antrum appears distended with hypoechoic appearance if fluid content is present (B). The gastric

just right of the midline, surrounded by the left lobe of the liver anteriorly and by the pancreas posteriorly. When the antrum was collapsed and flat, it was deemed to be empty (Figure A). If the antrum was a distended cavity, it was deemed to have some content. Internally, a hypoechoic appearance was considered clear fluid (Figure B), and a frosted glass-like appearance with intermediate echogenicity was considered solid content (Figure C). Once the presence of solid content was excluded, the patients were classified based on the Perlas grading scale ${ }^{17}$ (grade 0: the absence of appreciable gastric content in the antrum in both the supine and RLD positions; grade 1: clear fluid appreciable in the antrum only in the RLD position; grade 2: clear fluid in both the supine and RLD positions). The cross-sectional area (CSA) of the antrum in the RLD position $\left(\mathrm{CSA}_{\mathrm{RLD}}\right)$ was obtained using two perpendicular diameters and a standard formula as follows: $\mathrm{CSA}=(\mathrm{AP} \times \mathrm{CC} \times \pi) / 4(\mathrm{AP}=$ antero-posterior diameter and $\mathrm{CC}=$ cranio-caudal diameter). ${ }^{18}$ The diameters were measured from serosa to serosa between contractions. The amount of clear fluid was quantified by the gastric volume calculated using the $C S A_{R L D}$ via the following equation: gastric volume $(\mathrm{mL})=27.0+\left(14.6 \times \mathrm{CSA}_{\mathrm{RLD}}\right)-(1.28 \times$ age). ${ }^{19}$ A stomach was considered "empty" if content was absent or if it contained up to $1.5 \mathrm{~mL} \cdot \mathrm{kg}^{-1}$ of clear fluid. If a stomach contained solid content or $>1.5 \mathrm{~mL} \cdot \mathrm{kg}^{-1}$ of clear fluid, it was considered "full".

We calculated the minimum sample size needed to identify a minimum important increase in the incidence of a full stomach (6.2\%) in absolute terms in patients scheduled for elective laparoscopic cholecystectomy because of symptomatic gallbladder disease, based on a $6.2 \%$ incidence of full stomach in fasted surgical patients. ${ }^{9}$

SPSS software version 20 (IBM Inc., Armonk, NY, USA) was used to perform statistical analyses. The normality of the data was tested using the Shapiro-Wilk antrum has a frosted glass-like appearance with intermediate echogenicity if solid content is present $(\mathrm{C}) . \mathrm{A}=$ antrum; IVC = inferior vena cava $\mathrm{L}=$ liver; $\mathrm{P}=$ pancreas

test. Data are expressed as frequency (\%), mean (SD), or median [interquartile range]. The antral $\mathrm{CSA}_{\mathrm{RLD}}$ and gastric volume based on the gastric antral grades were analyzed using one-way analysis of variance or the Kruskal-Wallis test. A $P$ value $<0.05$ was considered statistically significant.

\section{Results}

A total of 150 patients were recruited between October 2017 and February 2019. Among these patients, 140 were included. Ten were excluded because they did not meet the inclusion criteria, and two were excluded because their data were incomplete. Consequently, 138 patients were included in the final analysis. The diagnoses of the included patients were as follows: calculous cholecystitis, $75 \%$; acalculous cholecystitis, $12 \%$; cholangitis, $4 \%$; and others (i.e., gall bladder polyps, cancer, adenomyomatosis, or cholesterolosis), $9 \%$.

The gastric antrum could be viewed in all patients in both the supine and RLD positions. Patient characteristics are presented in Table 1. Among the 138 patients, 120 (87\%) exhibited an empty stomach corresponding to a grade 0 antrum or up to $1.5 \mathrm{~mL} \cdot \mathrm{kg}^{-1}$ of clear fluid, and 18 patients $(13 \%)$ presented with a full stomach.

The measured antral $\mathrm{CSA}_{\mathrm{RLD}}$ and predicted gastric volume are presented according to the antral grades in Table 2. Sixty-five patients (47\%) had no content in the gastric antrum. Sixty-one patients (44\%) had fluid content: 55 patients $(40 \%)$ presented with a grade 1 antrum, and six patients (4\%) with a grade 2 antrum. Two out of the 55 patients with a grade 1 antrum and four out of the six patients with a grade 2 antrum had a gastric fluid volume of $>1.5 \mathrm{~mL} \cdot \mathrm{kg}^{-1}$. Twelve patients $(9 \%)$ had solid content in their stomach. Higher antral grades were correlated with 
Table 1 Patient characteristics

\begin{tabular}{llll}
\hline & $\begin{array}{l}\text { Empty stomach } \\
(n=120)\end{array}$ & $\begin{array}{l}\text { Full stomach } \\
(n=18)\end{array}$ & $\begin{array}{l}\text { All patients } \\
(n=138)\end{array}$ \\
\hline Age $(\mathrm{yr})$ & $55(17)$ & $59(16)$ & $56(17)$ \\
Sex $(\mathrm{M} / \mathrm{F})$ & $50 / 70$ & $5 / 13$ & $55 / 83$ \\
BMI $\left(\mathrm{kg} \cdot \mathrm{m}^{-2}\right)$ & $25.2(4.5)$ & $26.5(4.3)$ & $25.3(4.5)$ \\
Diabetes & $16(13.3)$ & $4(22.2)$ & $20(14.5)$ \\
GERD & $14(11.7)$ & $0(0.0)$ & $14(10.1)$ \\
Dyspepsia & $41(34.2)$ & $5(27.8)$ & $46(33.3)$ \\
Fasting time for clear liquids (hr) & $13.8[10.0-15.5]$ & $14.7[9.6-18.6]$ & $14.0[10.0-16.0]$ \\
Fasting time for solids (hr) & $14.8[13.5-17.0]$ & $15.5[14.0-18.6]$ & $14.9[13.5-17.0]$ \\
Diagnosis & & $14(77.8)$ & $104(75.4)$ \\
Calculous cholecystitis & $90(75.0)$ & $3(16.7)$ & $16(11.6)$ \\
Acalculous cholecystitis & $13(10.8)$ & $1(5.5)$ & $6(4.3)$ \\
Cholangitis & $5(4.2)$ & $0(0.0)$ & $12(8.7)$ \\
Others & $12(10.0)$ & \\
\hline
\end{tabular}

Values are mean (standard deviation), number of patients (\%), or median [interquartile range]. An empty stomach corresponds to a grade 0 antrum or stomach contents of up to $1.5 \mathrm{~mL} \cdot \mathrm{kg}^{-1}$ of clear fluid. A full stomach corresponds to solid content or $>1.5 \mathrm{~mL} \cdot \mathrm{kg}^{-1}$ of clear fluid in the stomach. $\mathrm{BMI}=$ body mass index; GERD = gastro-esophageal reflux disease

Table 2 Antral CSA $\mathrm{RLD}_{\text {and }}$ astric volume according to the gastric antral grades

\begin{tabular}{|c|c|c|c|c|c|}
\hline & \multirow{2}{*}{$\begin{array}{l}\text { No content } \\
\text { Grade } 0 \\
(n=65)\end{array}$} & \multicolumn{2}{|l|}{ Clear fluid } & \multirow[t]{2}{*}{ Solids $(n=12)$} & \multirow[t]{2}{*}{$P$ value } \\
\hline & & $\begin{array}{l}\text { Grade } 1 \\
(n=55)\end{array}$ & $\begin{array}{l}\text { Grade } 2 \\
(n=6)\end{array}$ & & \\
\hline Antral CSA $\mathrm{RLD}\left(\mathrm{cm}^{2}\right)$ & $3.0(1.6)$ & $6.7(1.4)$ & $11.7(3.4)$ & N/A & $<0.001$ \\
\hline Predicted gastric volume (mL) & $13.8(20.4)$ & $51.8(29.8)$ & $136.5(52.6)$ & N/A & $<0.001$ \\
\hline Predicted gastric volume $\left(\mathrm{mL} \cdot \mathrm{kg}^{-1}\right)$ & $0.2(0.3)$ & $0.8(0.4)$ & $1.7(0.7)$ & N/A & $<0.001$ \\
\hline Patients with $>1.5 \mathrm{mg} \cdot \mathrm{kg}^{-1}$ & $0(0.0)$ & $2(3.6)$ & $4(66.7)$ & N/A & $<0.001$ \\
\hline
\end{tabular}

Values are mean (standard deviation) or number of patients $(\%)$

Gastric antral grades (grade 0: the absence of appreciable gastric content in the antrum in both the supine and RLD positions; grade 1: clear fluid appreciable in the antrum only in the right lateral decubitus position; grade 2: clear fluid in both the supine and right lateral decubitus positions)

$\mathrm{CSA}_{\mathrm{RLD}}=$ cross-sectional area in the right lateral decubitus position; N/A = not applicable

larger antral $\mathrm{CSA}_{\mathrm{RLD}}$ and greater gastric volume $(P<$ 0.001).

Among the 18 patients with a full stomach, 12 patients had solid content and six patients had clear fluid content with a predicted volume of more than $1.5 \mathrm{~mL} \cdot \mathrm{kg}^{-1}$. The characteristics of patients with a full stomach based on the type of residual gastric content are presented in Table 3.

When a full stomach was visualized by gastric ultrasound, a further plan for anesthesia and surgery was discussed and determined together by anesthesiologists, attending surgeons, and each patient. Consequently, anesthesia and surgery proceeded as planned without delay or cancellation. During the induction of anesthesia in patients with a full stomach, tracheal intubation with a rapid sequence induction was performed. There were no occurrences of aspiration during the perioperative period.

\section{Discussion}

This study showed that $13 \%$ of patients scheduled for elective laparoscopic cholecystectomy because of symptomatic gallbladder disease presented with a full stomach. This was defined as the presence of solid content or a measured fluid volume of $>1.5 \mathrm{~mL} \cdot \mathrm{kg}^{-1}$ in the stomach on the day of surgery, even though they had followed the recommended fasting guideline. 
Table 3 Patient characteristics based on the type of gastric content in patients with a full stomach

\begin{tabular}{lll}
\hline & Fluid $>1.5 \mathrm{~mL} \cdot \mathrm{kg}^{-1}(n=6)$ & $\begin{array}{c}\text { Solids } \\
(n=12)\end{array}$ \\
\hline Age $(\mathrm{yr})$ & & $72[52-77]$ \\
Sex $(\mathrm{M} / \mathrm{F})$ & $50[45-54]$ & $3 / 9$ \\
BMI $\left(\mathrm{kg} \cdot \mathrm{m}^{-2}\right)$ & $2 / 4$ & $26.8[22.6-30.6]$ \\
Diabetes & $24.6[23.4-24.6]$ & $4(33.3)$ \\
GERD & $0(0.0)$ & $0(0.0)$ \\
Dyspepsia & $0(0.0)$ & $3(25.0)$ \\
Fasting time for clear liquids (hr) & $2(33.3)$ & $14.7[8.9-17.0]$ \\
Fasting time for solids (hr) & $16.5[10.6-20.3]$ & $15.3[14.0-17.0]$ \\
\hline
\end{tabular}

Values are median [interquartile range] or number of patients (\%). A full stomach corresponds to solid content or $>1.5 \mathrm{~mL} \cdot \mathrm{kg}^{-1}$ of clear fluid in the stomach. $\mathrm{BMI}=$ body mass index; GERD $=$ gastro-esophageal reflux disease

The $13 \%$ incidence of a full stomach in our study was higher than in previous studies (2.7-6.2\% among the general surgical population). ${ }^{9,10}$ In the present study, we considered a full stomach to be the presence of solid content and a fluid volume of $>1.5 \mathrm{~mL} \cdot \mathrm{kg}^{-1}$ based on previous studies ${ }^{9}$; however, the minimum threshold at which the gastric volume increases the risk of aspiration is controversial. $^{20}$ Among the 18 patients (13\%) with a full stomach in our study, six patients $(4 \%)$ presented with $>$ $1.5 \mathrm{~mL} \cdot \mathrm{kg}^{-1}$ of clear fluid, and 12 patients $(9 \%)$ with solid content in their stomachs. Compared with previous studies, the incidence of $>1.5 \mathrm{~mL} \cdot \mathrm{kg}^{-1}$ gastric volume in our patients was similar to those of general surgical patients $(4.5 \%)^{9}$ and term pregnant women $(5 \%) .{ }^{6}$ The incidence of solid gastric content before laparoscopic cholecystectomy was higher than the incidence in general surgical patients $(1.7 \%),{ }^{9}$ severely obese patients $(0 \%)^{8}$ and term pregnant women $(0 \%)^{6}$

Concerning the distribution of the antral grades in this study, the proportions of grade $0(47 \%)$, grade $1(40 \%)$, and grade $2(4 \%)$ were comparable with those of previous studies; further, the grade distribution was $51 \%, 48 \%$, and $1 \%$ among term pregnant women ${ }^{6} ; 43 \%, 53.5 \%$, and $3.5 \%$ among general surgical patients ${ }^{17}$; and $40 \%, 55 \%$, and $5 \%$ among severely obese individuals. ${ }^{8}$ The mean predicted gastric volume corresponding to grade 2 was $1.7 \mathrm{~mL} \cdot \mathrm{kg}^{-1}$ in our study, which was comparable with previous findings (1.7 $\mathrm{mL} \cdot \mathrm{kg}^{-1}$ in pregnant women, ${ }^{6} 1.6 \mathrm{~mL} \cdot \mathrm{kg}^{-1}$ in severely obese patients, ${ }^{8}$ and $1.8 \mathrm{~mL} \cdot \mathrm{kg}^{-1}$ in general surgical patients). ${ }^{9}$

The higher incidence of a full stomach in our study might be related to gallbladder diseases. Patients with gallbladder diseases, such as gallstone disease, exhibit delayed gastric emptying because of various mechanisms, such no hormonal stimuli from the diseased gallbladder mucosa to mediate gastric motility, a reflex pyloroduodenal ileus resulting from inflammation in and around the gallbladder, or pericholecystic inflammatory adhesions that involve the pyloroduodenum. ${ }^{21}$

Currently, cholecystectomy is primarily performed using the laparoscope. Patients undergoing laparoscopic cholecystectomy are at a higher risk of perioperative pulmonary aspiration because intraabdominal pressure increases during the surgery. ${ }^{22}$ They also exhibit a high incidence of postoperative nausea and vomiting. Without antiemetic treatment, the incidence of postoperative nausea and vomiting after laparoscopic cholecystectomy is 47$72 \%,{ }^{23,24}$ which is higher than that for all surgical populations $(25-30 \%) .^{25}$ Furthermore, bile-stained fluid may be regurgitated, ${ }^{26}$ and the aspiration of this bilestained fluid can lead to serious complications. ${ }^{27}$

Dyspepsia is a common complaint among patients with gallbladder diseases. Nevertheless, it has been reported that delayed gastric emptying in patients with gallbladder diseases was not specifically associated with dyspepsia. ${ }^{12}$ Additionally, two patients who had a full stomach had fasted for nearly $24 \mathrm{hr}$ before the laparoscopic cholecystectomy. Long fasting time may not guarantee an empty stomach in some patients with delayed gastric emptying.

A bedside gastric ultrasound assessment is a simple, easy-to-perform, and noninvasive technique for evaluating the gastric content and volume compared with other conventional methods, such as scintigraphy, gastric impedance monitoring, and paracetamol absorption tests. $^{28}$ Nevertheless, the clinical significance of currently defined cut-off values for a full stomach using gastric ultrasonography is not clear. ${ }^{20}$ The incidence of pulmonary aspiration in the clinical practice $(0.031 \%)^{3}$ is much lower than the reported incidence of a full stomach using gastric ultrasonography $(2.7-6.2 \%) .^{9,10}$ A high residual gastric volume calculated using a mathematical model does not 
accurately relate to pulmonary aspiration. Furthermore, up to $5 \%$ of gastric ultrasound examinations may be inconclusive, and the diagnostic accuracy of gastric ultrasound (sensitivity, specificity, and positive and negative predictive values) to determine a full stomach remains to be studied. ${ }^{9,29}$

At the present time, there is a lack of robust evidence from randomized-controlled trials on what a full stomach detected by gastric ultrasound implies regarding the risk of perioperative pulmonary aspiration. Specifically, for fasted patients undergoing elective cholecystectomy, data on the outcomes associated with different management regimens are insufficient. These regimens include aspiration prophylaxis and a rapid sequence induction; cancellation or delay until sonographic resolution of the full stomach; or standard care. Nevertheless, bedside gastric ultrasound may be an informative and potentially important tool for risk assessment and safe anesthetic management. Further studies are required to delineate the clinical implications of gastric ultrasound assessment for determining aspiration risk on induction of general anesthesia.

In the present study, when gastric ultrasound assessment showed a full stomach, we discussed the timing of surgery with the surgeons and patients based on individual-specific risks and benefits. In all of these cases, anesthesia and surgery proceeded as planned without delay or cancellation. Fortunately, there was no perioperative pulmonary aspiration. Nevertheless, we acknowledge that a strong argument can be made that anesthesia and surgery should have been postponed until the full stomach status was definitely resolved (for patient safety). The residual gastric content and the use of laparoscopy are risk factors for perioperative pulmonary aspiration, ${ }^{4,22}$ and patient safety should be the first priority.

This study has several limitations. First, it is an observational single-cohort study and lacks a control group. Further studies with a control group are required to draw robust clinical inferences in these patients. Second, our sample size projection changed after the initial registration at ClinicalTrials.gov. This study was initially designed as an observational cohort study and the sample size was determined as 240 at the initial registration, considering the number of laparoscopic cholecystectomies in our centre for one year. Afterwards, we changed the sample size projection on the basis of null hypothesis significance testing to identify a minimally important increase in the incidence of a full stomach based on the reported incidence of a full stomach $(6.2 \%)$ among fasted surgical patients. ${ }^{9}$ Therefore, we changed the sample size to 140 at ClinicalTrials.gov. Ideally, we would have conducted this study in compliance with its original design. Third, ultrasonographic examinations were performed by two investigators; however, it has been reported that quantitative and qualitative gastric ultrasound assessments are highly reproducible with high intra- and inter-observer reliability. ${ }^{30}$ Fourth, most patients fasted for a longer time than is recommended by the guidelines. Therefore, the results of the present study may differ from those whose participants fasted for the minimum time suggested by the preoperative fasting guidelines. Fifth, the residual gastric volume was not confirmed by a direct method such as endoscopy or gastric suction. Lastly, this study was performed in an Asian population, so our results may not extrapolate to other ethnic populations because of possible race-related differences in the pathophysiology of gallbladder diseases.

In conclusion, $13 \%$ of the patients scheduled for elective laparoscopic cholecystectomy because of symptomatic gallbladder disease presented with an ultrasonographically defined full stomach before the induction of anesthesia despite following the fasting guidelines. This finding might be due to delayed gastric emptying in patients with gallbladder diseases. Bedside gastric ultrasonography is a simple-to-use and effective diagnostic tool during the perioperative period, but its clinical implications are still uncertain. Further studies are required to delineate the clinical implications of our findings.

Author contributions Jee-Eun Chang, Hyerim Kim, Dongwook Won, Jung-Man Lee, Ji-Yoon Jung, Seong-Won Min, and Jin-Young Hwang helped design the study, conduct the study, analyze the data, and write the manuscript. All authors have seen the original study data and reviewed the data analysis. Jin-Young Hwang was responsible for archiving the study files.

Acknowledgement The authors would like to thank Sohee Oh, PhD of the Department of Biostatistics in Seoul Metropolitan Government Seoul National University Boramae Medical Center for statistical advice.

\section{Conflicts of interest None.}

Funding statement This study was not supported by any funding sources.

Editorial responsibility This submission was handled by Dr. Philip M. Jones, Associate Editor, Canadian Journal of Anesthesia.

\section{References}

1. Cotton BR, Smith G. The lower oesophageal sphincter and anaesthesia. Br J Anaesth 1984; 56: 37-46.

2. Vanner $R G$, Pryle BJ, O'Dwyer JP, Reynolds F. Upper oesophageal sphincter pressure and the intravenous induction of anaesthesia. Anaesthesia 1992; 47: 371-5.

3. Warner MA, Warner ME, Weber JG. Clinical significance of pulmonary aspiration during the perioperative period. Anesthesiology 1993; 78: 56-62. 
4. Landreau B, Odin $I$, Nathan $N$. Pulmonary aspiration: epidemiology and risk factors (French). Ann Fr Anesth Reanim 2009; 28: 206-10.

5. Anonymous. Practice Guidelines for Preoperative Fasting and the Use of Pharmacologic Agents to Reduce the Risk of Pulmonary Aspiration: Application to Healthy Patients Undergoing Elective Procedures: An Updated Report by the American Society of Anesthesiologists Task Force on Preoperative Fasting and the Use of Pharmacologic Agents to Reduce the Risk of Pulmonary Aspiration. Anesthesiology 2017; 126: 376-93.

6. Arzola C, Perlas A, Siddiqui NT, Carvalho JC. Bedside gastric ultrasonography in term pregnant women before elective cesarean delivery: a prospective cohort study. Anesth Analg 2015; 121 : 752-8.

7. Sabry R, Hasanin A, Refaat S, Abdel Raouf S, Abdallah AS, Helmy $N$. Evaluation of gastric residual volume in fasting diabetic patients using gastric ultrasound. Acta Anaesthesiol Scand 2019; 63: 615-9.

8. Kruisselbrink R, Arzola C, Jackson T, Okrainec A, Chan V, Perlas A. Ultrasound assessment of gastric volume in severely obese individuals: a validation study. Br J Anaesth 2017; 118: 7782.

9. Van de Putte P, Vernieuwe L, Jerjir A, Verschueren L, Tacken M, Perlas $A$. When fasted is not empty: a retrospective cohort study of gastric content in fasted surgical patients. Br J Anaesth 2017; 118: 363-71.

10. Ohashi $Y$, Walker JC, Zhang $F$, et al. Preoperative gastric residual volumes in fasted patients measured by bedside ultrasound: a prospective observational study. Anaesth Intensive Care 2018; 46: 608-13.

11. Stinton LM, Shaffer EA. Epidemiology of gallbladder disease: cholelithiasis and cancer. Gut Liver 2012; 6: 172-87.

12. Watson $R G$, Love $A H$. Gastric emptying in patients with flatulent dyspepsia, with and without gallbladder disease. Scand J Gastroenterol 1987; 22: 47-53.

13. Agresta F, Bedin N. Gallstone ileus as a complication of acute cholecystitis. Laparoscopic diagnosis and treatment. Surg Endos 2002; . https://doi.org/10.1007/s00464-002-4215-4.

14. Van de Putte P, Perlas A. Ultrasound assessment of gastric content and volume. Br J Anaesth 2014; 113: 12-22.

15. Bouvet L, Mazoit JX, Chassard D, Allaouchiche B, Boselli E, Benhamou D. Clinical assessment of the ultrasonographic measurement of antral area for estimating preoperative gastric content and volume. Anesthesiology 2011; 114: 1086-92.

16. Perlas A, Chan VW, Lupu CM, Mitsakakis N, Hanbidge A. Ultrasound assessment of gastric content and volume. Anesthesiology 2009; 111: 82-9.
17. Perlas A, Davis L, Khan M, Mitsakakis N, Chan VW. Gastric sonography in the fasted surgical patient: a prospective descriptive study. Anesth Analg 2011; 113: 93-7.

18. Bolondi L, Bortolotti M, Santi V, Calletti T, Gaiani S, Labo G. Measurement of gastric emptying time by real-time ultrasonography. Gastroenterology 1985; 89: 752-9.

19. Perlas A, Mitsakakis N, Liu L, et al. Validation of a mathematical model for ultrasound assessment of gastric volume by gastroscopic examination. Anesth Analg 2013; 116: 357-63.

20. Van de Putte P, Perlas A. The link between gastric volume and aspiration risk. In search of the Holy Grail? Anaesthesia 2018; 73: 274-9.

21. Ibrarullah M, Mittal BR, Agarwal DK, Das BK, Kaushik SP. Gastric emptying in patients with gallstone disease with or without dyspepsia: effect of cholecystectomy. Aust N Z J Surg 1994; 64: 247-50.

22. Asai T. Editorial II: who is at increased risk of pulmonary aspiration? Br J Anaesth 2004; 93: 497-500.

23. Helmy SA. Prophylactic anti-emetic efficacy of ondansetron in laparoscopic cholecystectomy under total intravenous anaesthesia. A randomised, double-blind comparison with droperidol, metoclopramide and placebo. Anaesthesia 1999; 54: 266-71.

24. Naguib M, el Bakry AK, Khoshim MH, et al. Prophylactic antiemetic therapy with ondansetron, tropisetron, granisetron and metoclopramide in patients undergoing laparoscopic cholecystectomy: a randomized, double-blind comparison with placebo. Can J Anaesth 1996; 43: 226-31.

25. Kovac AL. Prevention and treatment of postoperative nausea and vomiting. Drugs 2000; 59: 213-43.

26. Maltby JR, Beriault MT, Watson NC. Use of the laryngeal mask is not contraindicated for laparoscopic cholecystectomy. Anaesthesia 2001; 56: 800-2.

27. Porembka DT, Kier A, Sehlhorst S, Boyce S, Orlowski JP, Davis $K J r$. The pathophysiologic changes following bile aspiration in a porcine lung model. Chest 1993; 104: 919-24.

28. Moreira TV, McQuiggan M. Methods for the assessment of gastric emptying in critically ill, enterally fed adults. Nutr Clin Pract 2009; 24: 261-73.

29. Perlas A, Arzola C, Van de Putte P. Point-of-care gastric ultrasound and aspiration risk assessment: a narrative review. Can J Anesth 2018; 65: 437-48.

30. Kruisselbrink $R$, Arzola C, Endersby $R$, Tse C, Chan V, Perlas A. Intra- and interrater reliability of ultrasound assessment of gastric volume. Anesthesiology 2014; 121: 46-51.

Publisher's Note Springer Nature remains neutral with regard to jurisdictional claims in published maps and institutional affiliations. 